\title{
Difference in balance measures between patients with chronic ankle instability and patients after an acute ankle inversion trauma
}

\author{
J. S. de Vries $\cdot$ I. Kingma $\cdot$ L. Blankevoort $\cdot$ \\ C. N. van Dijk
}

Received: 22 April 2009/Accepted: 16 February 2010/Published online: 12 March 2010

(C) The Author(s) 2010. This article is published with open access at Springerlink.com

\begin{abstract}
Neuromuscular control of the ankle is disturbed in patients with chronic ankle instability due to an initial ankle inversion trauma. Static balance is assumed to be a measure for this disturbance. Functional (ankle) scores are another way to evaluate ankle impairment. The hypothesis was that there is a difference in static balance measures between small groups of healthy subjects, patients after an acute ankle inversion trauma and patients with chronic ankle instability and that static balance measures correlate well with functional scores. Static balance in healthy subjects $(N=15)$, patients after a primary ankle inversion injury $(N=14)$ and patients with chronic ankle instability $(N=23)$ was tested with a single leg test on a force plate (Postural Sway test) and on a compliant floor (Simple Balance test). Functional impairment was evaluated with the Karlsson, AOFAS and SF-36 (ankle) scores. There was a statistically significant and clinically relevant difference in functional (ankle) scores, but not a statistically significant difference in balance measures between the groups. Balance measures did not correlate to the functional scores. It was concluded that, despite a clinically relevant difference in functional outcome measures between the groups, static balance measures do not appear to be useful for clinical application in the individual patient.
\end{abstract}

J. S. de Vries $(\bowtie) \cdot$ L. Blankevoort · C. N. van Dijk Department of Orthopaedic Surgery, G4-222,

Academic Medical Center, Orthopaedic Research Center

Amsterdam, P.O. Box 22660, 1100 DD Amsterdam,

The Netherlands

e-mail: jsduvries@gmail.com

I. Kingma

Faculty of Human Movement Sciences, Research Institute Move, VU University, Van der Boechorststraat 7, 1081 BT Amsterdam,

The Netherlands
Keywords Ankle $\cdot$ Balance $\cdot$ Neuromuscular . Instability $\cdot$ Acute $\cdot$ Chronic

\section{Introduction}

Functional treatment of an acute ankle inversion trauma leads to full recovery in the majority of the patients but ten to forty percent of these patients suffer from recurrent sprains or giving way $[11,12,25]$. If symptoms of instability persist longer than 6 months this is referred to as 'chronic ankle instability' [11].

Early identification of those subjects who are susceptible to development of chronic ankle instability, e.g., by assessing laxity, would be helpful for setting up costeffective prevention programs. However, increased laxity of the lateral ankle ligaments is not present in all patients with recurrent giving way and is probably only partially responsible for the symptoms [24]. Chronic ankle instability without clearly increased laxity is also referred to as functional instability.

Contrary to increased laxity, all patients with chronic ankle instability are thought to have disturbed neuromuscular control of the ankle caused by damage to muscles, receptors or nerves by the initial ankle inversion injury $[2,7$, $19,24]$. Neuromuscular control of the ankle can be evaluated by joint position sense, peroneal reaction time, magnitude of the activity of the peroneal muscles (EMG measurement) and by balance tests [2, 7, 19]. Balance tests can be static (single leg stance) or dynamic (e.g., single leg hop test) $[2,19]$. The advantage of static balance tests is that they are easier to perform and safer than dynamic tests, and some tests can be performed outside a laboratory [20, 21].

Several authors have found a difference in static balance between injured and non-injured ankles and between 
athletes with and without functional instability [3, 14, 24]. In addition, patients undergoing physiotherapeutic rehabilitation for ankle instability show improvement in balance [5]. A decreased ability to maintain balance in athletes without a recent history of ankle sprains appears to be a predictor for future sprains [15, 23].

Another way to measure functional impairment is the use of functional (ankle) scores. The Karlsson and AOFAS are well-known scores to evaluate the ankle, whereas the SF-36 is a widely used score to assess physical and mental functioning [9, 10, 13].

While balance tests are widely used in research, clinical applications are scarce and they have not yet adequately been validated. The question addressed was whether balance tests can be used as a tool to discriminate between at risk and not at risk for chronic functional instability in an individual patient. As a gold standard for validation is lacking, the best way to evaluate such tests may be to compare tests between groups of patients that are expected to show functional differences. As differences between balance tests are only clinically relevant if they show up in small groups, the aim of this study was to evaluate whether there is a difference in static balance measures between small groups of healthy subjects, patients after an acute ankle inversion trauma and patients with chronic ankle instability and to compare the same groups using functional (ankle) scores.

The hypotheses were (1) that static balance measures in a group of patients with chronic ankle instability are worse than in a group of patients after an acute ankle sprains, (2) that both groups have worse measures than healthy subjects and (3) that balance measures correlate well with functional scores.

\section{Materials and methods}

The study was designed as a cross-sectional survey. Two static single leg balance tests were used, the Postural Sway test and the Simple Balance test [6, 8, 17, 23, 24]. Functional (ankle) scores were used to evaluate functional impairment [9, 10, 13].

The study was performed from 2004 to 2006 and was approved by the internal review board of the Academic Medical Center (Amsterdam, The Netherlands) for the participation of human subjects. All subjects were informed of the procedures and signed a consent form prior to participation.

\section{Subjects}

Subject groups were a Healthy group $(n=15)$, an Acute group ( $n=14$ ), consisting of pain-free subjects $6-8$ weeks after an acute ankle inversion trauma, and a Chronic group
( $n=23)$, consisting of subjects with chronic lateral ankle instability [11].

Exclusion criteria were the following: a history of ankle fracture or surgery, any systemic or generalized disorder affecting the locomotor system for all subjects and a VASscore for ankle pain greater than 50 (on a scale from 0 to 100), for the Acute and the Chronic group [18]. Nineteen of the subjects in the Chronic group had increased laxity of ankle ligaments, as assessed with the manual anterior drawer test [26].

Protocol and instrumentation

After physical examination of both ankles, including the manual anterior drawer test in all patients, and filling out the forms for the functional (ankle-) scores for the affected ankle, the balance tests were performed. In the healthy group, the left and right sides were randomly assigned as 'Affected' and 'Non-affected'.

In the Postural Sway test [6, 17, 23, 24], the subjects had to keep balance in one-leg stance on a portable forceplate (AMTI DSA6; Advanced Mechanical Technology, Inc.; Watertown, MA, USA). Four conditions were tested, each for 1 min: Eyes Open Affected leg (EOA), Eyes Open Non-affected leg (EON), Eyes Closed Affected leg (ECA) and Eyes Closed Non-affected leg (ECN). The center of pressure (COP) was measured at a sample rate of $50 \mathrm{~Hz}$. Matlab (The MathWorks, Inc; Natick, MA, USA) was used to calculate the mean velocity of displacement of the COP (Speed-COP) and the root mean squared distance between the COP and the mean COP (RMS-COP).

In the Simple Balance test [8], the subjects had to keep balance in one-leg stance on a compliant floor (gymnastic mat) during $1 \mathrm{~min}$ for the same four conditions as with the Postural Sway test. The number of failures and time to first failure were registered.

Functional impairment was assessed, using two ankle scores: the Karlsson and AOFAS-score [10, 13]. The SF-36 score was used as a measure for general functioning $[9,27]$.

\section{Outcome measures}

The primary outcome measure was RMS-COP-EOA (m) of the Postural Sway test. Secondary outcome measures were all other measures of the balance tests and functional scores as described earlier.

Statistical analyses

The differences in balance measures between groups, between the Affected and Non-affected sides within groups, between the Eyes Open and Eyes Closed 
conditions within groups, the differences in functional (ankle) scores between groups and the correlations between balance tests and functional scores were statistically analyzed using SPSS for Windows (version 12.0, SPSS Inc., Chicago, USA). Due to skewed distributions, the data are presented as median and range and were analyzed using non-parametric tests. A significance level of $P<0.05$ was used throughout the data analysis.

Comparison between the three groups was examined with the Kruskal-Wallis test, except for the comparison regarding sex distribution, which was analyzed with the Pearson chi-square test. Post hoc analysis between groups in pairs was examined with the Mann-Whitney $U$ test. For comparisons within groups, the Wilcoxon signed ranks test was used. Correlations between balance tests and functional scores were calculated using the Pearson Correlation test.

\section{Results}

No statistically significant differences were found regarding patients characteristics (Table 1) and the primary and secondary outcome measures of the balance tests (Table 2) when comparing the three groups.

In the Chronic group, the Affected side had a significantly worse score than the Non-affected side with both parameters of the Simple Balance test with Eyes Open, whereas within all groups, subjects had a worse score with Eyes Closed compared to Eyes Open with both balance tests for all parameters (Table 3).

All three physical functional scores showed a significant group effect (Table 4). Post hoc analyses showed higher scores for the healthy than for the acute group in the each of the three functional scores. The scores of the chronic group were lower than the healthy and acute groups according the Karlsson scale, lower than the healthy group according the AOFAS scale and higher than the acute group according the physical component of the SF-36 scale.

There were substantial correlations among balance test parameters, as well as among functional ankle scores, but

Table 1 Subject characteristics

\begin{tabular}{llllll}
\hline & & Healthy & Acute & Chronic & $P$ value \\
\hline$N$ & & 15 & 14 & 23 & \\
Sex & Male/female & $6 / 9$ & $8 / 6$ & $11 / 12$ & n.s. ${ }^{*}$ \\
Age & Median (range) & $29(23-58)$ & $38(18-56)$ & $29(18-63)$ & n.s.** \\
ADT & Positive (\%) & $0(0)$ & $5(36)$ & $19(83)$ & \\
\hline
\end{tabular}

$A D T$ Anterior Drawer Test (manual)

* Pearson chi-square test, ** Kruskal-Wallis test no correlations between any of the balance test parameters and the functional scores or between the functional ankle scores and the physical component scale of the SF-36 (Table 5).

\section{Discussion}

The most important finding of this study is that there was no difference in static balance measures between small groups of healthy subjects, patients after an acute ankle inversion trauma and patients with chronic ankle instability. It was assumed that chronic ankle instability is caused by disturbed neuromuscular control and that the static balance tests applied in this study are good methods to evaluate (disturbed) neuromuscular control. The hypotheses were that balance measures on average would be best in the healthy subjects, worst in patients with chronic ankle instability and that patients after a primary ankle inversion trauma would score in between these two groups. Since no difference in balance measures between the groups was found, and the balance tests did not correlate with the functional scores, the hypotheses were not confirmed.

The current study evaluated the correlation between static balance measures and functional (ankle) scores in healthy subjects, patients after an acute ankle sprain and patients with chronic ankle instability in one trial. Only one other study was found that compares more or less the same groups for proprioception. Willems et al. [28] found a statistically significant difference between subjects with chronic ankle instability compared to the acute group and healthy subjects with a joint position test and an evertor muscle strength test. The 'acute' group consisted of subjects with a history of one to three sprains in up to 5 years. As in the present study, no difference between the acute group and the healthy subjects was found.

Several studies have reported a difference in static balance measures between 'acute' and healthy patients, between 'chronic' and healthy patients regarding ankle injuries and that worse balance measures might predict future ankle injury [2-4, 7, 8, 14, 16, 19, 23, 24]. This, however, was not confirmed in the present study. The lack of statistically significant differences between groups with static balance measures in the current study confirmed similar findings in some other studies [1, 22].

One limitation of the present study was that we did not perform an a priori power calculation. The magnitude of the groups in the present study thus requires consideration, and we cannot exclude that, in substantially larger groups, differences between groups could become statistically significant in the current study. The decision not to perform a power calculation was related to the lack of consistent data in the literature and the number of outcome variables 
Table 2 Results of the Postural Sway and Simple Balance tests-differences between groups for the affected side (Results are given as median (range), $P$ values are for the comparison of the three groups together)

\begin{tabular}{llll} 
Healthy group & Acute group & Chronic group & $P$ value* \\
Median (min-max) & Median (min-max) & Median (min-max) & \\
\hline
\end{tabular}

\begin{tabular}{|c|c|c|c|c|}
\hline \multicolumn{5}{|l|}{ Postural Sway test } \\
\hline RMS-COP-EOA (m) & $0.012(0.007-0.026)$ & $0.011(0.008-0.016)$ & $0.011(0.008-0.027)$ & n.s. \\
\hline RMS-COP-ECA (m) & $0.018(0.009-0.035)$ & $0.020(0.015-0.026)$ & $0.021(0.008-0.043)$ & n.s. \\
\hline Speed-COP-EOA (m/s) & $0.038(0.025-0.089)$ & $0.040(0.030-0.063)$ & $0.043(0.025-0.064)$ & n.s. \\
\hline Speed-COP-ECA (m/s) & $0.076(0.044-0.112)$ & $0.091(0.056-0.132)$ & $0.083(0.041-0.208)$ & n.s. \\
\hline \multicolumn{5}{|l|}{ Simple Balance test } \\
\hline Number of Failures-EOA (/min) & $0(0-16)$ & $0(0-9)$ & $1(0-10)$ & n.s. \\
\hline Number of Failures-ECA (/min) & $11(4-18)$ & $13(4-17)$ & $13(5-19)$ & n.s. \\
\hline Time to first failure-EOA (s) & $60(3-60)$ & $60(4-60)$ & $55(1-60)$ & n.s. \\
\hline Time to first failure-ECA (s) & $3(1-13)$ & $2(1-7)$ & $3(1-17)$ & n.s. \\
\hline
\end{tabular}

$R M S$-COP root mean square of the distance of separate COP to the average COP, Speed-COP average speed of COP, EOA Eyes Open Affected side, ECA Eyes Closed Affected side

* Kruskal-Wallis test

Table 3 Results of the Postural Sway and Simple Balance tests (medians only)—comparisons of Eyes Open versus Eyes Closed conditions and Affected side versus Non-affected side within the Chronic and the Acute group ( $P$ values are for the pair-wise comparisons between Eyes Open and Eyes Closed conditions and between Affected and Non-affected sides)

\begin{tabular}{|c|c|c|c|c|c|c|}
\hline & \multicolumn{3}{|c|}{ Acute group } & \multicolumn{3}{|c|}{ Chronic group } \\
\hline & $A$ & $N$ & $P$ value & $A$ & $N$ & $P$ value* \\
\hline \multicolumn{7}{|l|}{ Postural Sway } \\
\hline RMS-COP-EO & 0.011 & 0.012 & n.s. & 0.011 & 0.012 & n.s. \\
\hline RMS-COP-EC & 0.020 & 0.021 & n.s. & 0.021 & 0.024 & n.s. \\
\hline$P$ value* & 0.002 & 0.001 & & $<0.001$ & $<0.001$ & \\
\hline Speed-COP-EO (cm/s) & 0.040 & 0.035 & n.s. & 0.043 & 0.038 & n.s. \\
\hline Speed-COP-EC (cm/s) & 0.091 & 0.093 & n.s. & 0.083 & 0.084 & n.s. \\
\hline$P$ value* & 0.001 & 0.001 & & $<0.001$ & $<0.001$ & \\
\hline \multicolumn{7}{|l|}{ Simple Balance } \\
\hline $\mathrm{Nr}$ of failures-EO (/min) & 0 & 0 & n.s. & 1 & 0 & 0.02 \\
\hline $\mathrm{Nr}$ of failures-EC (/min) & 13 & 11 & n.s. & 13 & 12 & n.s. \\
\hline$P$ value* & 0.001 & 0.001 & & $<0.001$ & $<0.001$ & \\
\hline Time to first failure-EO (s) & 60 & 60 & n.s. & 55 & 60 & 0.03 \\
\hline Time to first failure-EC (s) & 2 & 2 & n.s. & 3 & 4 & n.s. \\
\hline$P$ value* & 0.001 & 0.001 & & $<0.001$ & $<0.001$ & \\
\hline
\end{tabular}

$A$ Affected side, $N$ Non-affected side, $R M$-COP root mean square of the distance of separate COP to the average COP, Speed-COP average speed of COP, EO Eyes Open, EC Eyes Closed

* Wilcoxon signed ranks test

we wanted to test. The Simple Balance test used in this study was based on the test used by Jerosch et al. [8], who found a difference between comparable small groups of subjects. However, the majority of other studies that did find a difference in neuromuscular control had substantially more subjects, ranging from 30 to 127 in the affected group [3-5, 14-16, 23].

However, the question is whether small statistically significant differences are clinically relevant. To be useful for clinical application, a test should be capable to show differences in small groups as well. As we did not find such differences with the balance tests, whereas differences were statistically significant for the functional scores, the present results indicate that if balance test differences would show up in larger groups, such differences would be small and clinically not relevant nor useful for differentiating between 'at risk' and 'not at risk' for developing chronic ankle instability after an initial inversion injury in an individual patient. 
Table 4 Results of the functional scores ( $P$ values are for the comparison of the three groups together)

\begin{tabular}{|c|c|c|c|c|}
\hline & $\begin{array}{l}\text { Healthy group } \\
\text { Median (min-max) }\end{array}$ & $\begin{array}{l}\text { Acute group } \\
\text { Median (min-max) }\end{array}$ & $\begin{array}{l}\text { Chronic group } \\
\text { Median (min-max) }\end{array}$ & $P$ value* \\
\hline Karlsson-score & $100(100-100)$ & $89(42-100)$ & $78(42-97)$ & $<0.001$ \\
\hline AOFAS-score & $100(100-100)$ & $90(67-100)$ & $85(46-100)$ & $<0.001$ \\
\hline SF-36-Physical & $55(47-70)$ & $48(28-59)$ & $53(33-67)$ & 0.006 \\
\hline SF-36-Mental & $55(27-59)$ & $50(33-57)$ & $53(23-61)$ & n.s. \\
\hline
\end{tabular}

SF-36-Physical Physical Component Scale of the SF-36, SF-36-Mental Mental component scale of the SF-36

* Kruskal-Wallis test

Table 5 Correlations among Balance tests and between Balance tests and functional scores

\begin{tabular}{|c|c|c|c|c|}
\hline & \multirow{2}{*}{$\begin{array}{l}\text { Postural control } \\
\text { Speed-COP }\end{array}$} & \multicolumn{2}{|l|}{ Simple balance } & \multirow[t]{2}{*}{ Functional scores } \\
\hline & & No. of failures & Time to first failures & \\
\hline \multicolumn{5}{|l|}{ Postural control } \\
\hline RMS-COP & $0.84(P<0.001)^{*}$ & $0.77(P<0.001)^{*}$ & $-0.65(P<0.001)^{*}$ & No correlation* \\
\hline Speed-COP & & $0.74(P<0.001)^{*}$ & $-0.66(P<0.001)^{*}$ & No correlation* \\
\hline \multicolumn{5}{|l|}{ Simple balance } \\
\hline No. of failures & & & $-0.83(P<0.001)^{*}$ & No correlation* \\
\hline Time to first failures & & & & No correlation* \\
\hline
\end{tabular}

RMS-COP root mean square of the distance of separate COP to the average COP, Speed-COP average speed of COP

* Pearson correlation coefficient $(P$ value $)$

\section{Conclusions}

There is no statistically significant difference in static balances measures between small groups of healthy individuals, patients shortly after a primary acute ankle inversion injury and patients suffering chronic ankle instability, despite a statistically significant and clinically relevant difference in functional outcome measures between the groups. The outcome measures from the Postural Sway and the Simple Balance tests correlated with each other but not with functional (ankle) scores. Static balance measures do not appear to be useful for clinical application in the individual patient.

Acknowledgments We would like to thank Ms M vd Eijnden, student Movement-technology at the Haagse Hogeschool (Den Haag, NL) for her help with the data acquisition and analysis.

Open Access This article is distributed under the terms of the Creative Commons Attribution Noncommercial License which permits any noncommercial use, distribution, and reproduction in any medium, provided the original author(s) and source are credited.

\section{References}

1. Baier M, Hopf T (1998) Ankle orthoses effect on single-limb standing balance in athletes with functional ankle instability. Arch Phys Med Rehabil 79:939-944
2. Becker HP, Rosenbaum D (1999) Chronic recurrent ligament instability on the lateral ankle. Orthopade 28:483-492

3. Cornwall MW, Murrell P (1991) Postural sway following inversion sprain of the ankle. J Am Podiatr Med Assoc 81:243247

4. Docherty CL, Valovich McLeod TC, Shultz SJ (2006) Postural control deficits in participants with functional ankle instability as measured by the balance error scoring system. Clin J Sport Med $16: 203-208$

5. Eils E, Rosenbaum D (2001) A multi-station proprioceptive exercise program in patients with ankle instability. Med Sci Sports Exerc 33:1991-1998

6. Geurts AC, Nienhuis B, Mulder TW (1993) Intrasubject variability of selected force-platform parameters in the quantification of postural control. Arch Phys Med Rehabil 74:1144-1150

7. Hertel J (2002) Functional anatomy, pathomechanics, and pathophysiology of lateral ankle instability. J Athl Train 37:364-375

8. Jerosch J, Hoffstetter I, Bork H, Bischof M (1995) The influence of orthoses on the proprioception of the ankle joint. Knee Surg Sports Traumatol Arthrosc 3:39-46

9. Jerosch J, Schoppe R (2000) Midterm effects of ankle joint supports on sensomotor and sport-specific capabilities. Knee Surg Sports Traumatol Arthrosc 8:252-259

10. Karlsson J, Bergsten T, Petersen L (1991) Evaluation of ankle function: the use of a scoring scale. Foot 1:15-19

11. Karlsson J, Lansinger O (1992) Lateral instability of the ankle joint. Clin Orthop Rel Res 276:253-261

12. Kerkhoffs GM, Handoll HH, de Bie R, Rowe BH, Struijs PA (2002) Surgical versus conservative treatment for acute injuries of the lateral ligament complex of the ankle in adults. Cochrane Database Syst Rev CD000380

13. Kitaoka HB, Alexander IJ, Adelaar RS, Nunley JA, Myerson MS, Sanders M (1994) Clinical rating systems for the ankle-hindfoot, midfoot, hallux, and lesser toes. Foot Ankle Int 15:349-353 
14. Leanderson J, Wykman A, Eriksson E (1993) Ankle sprain and postural sway in basketball players. Knee Surg Sports Traumatol Arthrosc 1:203-205

15. McGuine TA, Greene JJ, Best T, Leverson G (2000) Balance as a predictor of ankle injuries in high school basketball players. Clin J Sport Med 10:239-244

16. McKeon PO, Hertel J (2008) Spatiotemporal postural control deficits are present in those with chronic ankle instability. BMC Musculoskelet Disord 9:76

17. Njiokiktjien C, de Rijke W (1972) The recording of Romberg' test and its application in neurology. Agressologie 13(Suppl C):1-7

18. Price DD, McGrath PA, Rafii A, Buckingham B (1983) The validation of visual analogue scales as ratio scale measures for chronic and experimental pain. Pain 17:45-56

19. Richie DH Jr (2001) Functional instability of the ankle and the role of neuromuscular control: a comprehensive review. J Foot Ankle Surg 40:240-251

20. Riemann BL, Guskiewicz KM (2000) Effects of mild head injury on postural stability as measured through clinical balance testing. J Athl Train 35:19-25

21. Riemann BL, Guskiewicz KM, Shields EW (1999) Relationship between clinical and forceplate measures of postural stability. J Sport Rehabil 8:71-82
22. Ross SE, Guskiewicz KM (2004) Examination of static and dynamic postural stability in individuals with functionally stable and unstable ankles. Clin J Sport Med 14:332-338

23. Tropp H, Ekstrand J, Gillquist J (1984) Stabilometry in functional instability of the ankle and its value in predicting injury. Med Sci Sports Exerc 16:64-66

24. Tropp H, Odenrick P, Gillquist J (1985) Stabilometry recordings in functional and mechanical instability of the ankle joint. Int $\mathrm{J}$ Sports Med 6:180-182

25. Valderrabano V, Wiewiorski M, Frigg A, Hintermann B, Leumann A (2007) Chronic ankle instability. Unfallchirurg 110:691700

26. van Dijk CN, Mol BW, Lim LS, Marti RK, Bossuyt PM (1996) Diagnosis of ligament rupture of the ankle joint. Physical examination, arthrography, stress radiography and sonography compared in 160 patients after inversion trauma. Acta Orthop Scand 67:566-570

27. Ware JE Jr, Sherbourne CD (1992) The MOS 36-item short-form health survey (SF-36). I. Conceptual framework and item selection. Med Care 30:473-483

28. Willems T, Witvrouw E, Verstuyft J, Vaes P, De Clercq D (2002) Proprioception and muscle strength in subjects with a history of ankle sprains and chronic instability. J Athl Train 37:487-493 